San Jose State University

SJSU ScholarWorks

Master's Theses

Master's Theses and Graduate Research

1990

\title{
Effects of twenty-first century work force demographics on attitudes towards management approaches
}

Sharon R. Hertle

San Jose State University

Follow this and additional works at: https://scholarworks.sjsu.edu/etd_theses

\section{Recommended Citation}

Hertle, Sharon R., "Effects of twenty-first century work force demographics on attitudes towards management approaches" (1990). Master's Theses. 3323.

DOI: https://doi.org/10.31979/etd.82xj-phhx

https://scholarworks.sjsu.edu/etd_theses/3323

This Thesis is brought to you for free and open access by the Master's Theses and Graduate Research at SJSU ScholarWorks. It has been accepted for inclusion in Master's Theses by an authorized administrator of SJSU ScholarWorks. For more information, please contact scholarworks@sjsu.edu. 


\section{INFORMATION TO USRES}

The most advanced technology has been used to photograph and reproduce this manuscript from the microfilm master. UMI films the text directly from the original or copy submitted! Thus, some thesis and dissertation copies are in typewriter face, while thers may be from any type of computer printer.

The quality of this reproduction is dependent upon the quality of the copy submitted. Broken or indistinct print, colored or poor quality illustrations and photographs, print bleedthrough, substandard margins, and improper alignment can adversely affect reproduction.

In the unlikely event that the author did not send UMI a complete manuscript and there are missing pages, these will be noted. Also, if unauthorized copyright material had to be removed, a note will indicate the deletion.

Oversize materials (e.g., maps, drawings, charts) are reproduced by sectioning the orighal, beginning at the upper left-hand corner and continuing from left to right in equal sections with small overlaps. Each original is also photographed in one exposure and is included in reduced form at the back of the book.

Photographs included in the original manuscript have been reproduced xerographically in this copy. Higher quality $6 "$ " 1 9" black and white photographic prints are available for any photographs or illustrations appearing in this copy for an additional charge. Contact UMI directly to order.

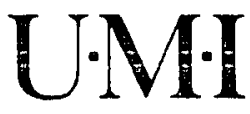

University Microfilms International

A Bell \&. Howell information Company 

Order Number 1341674

Effects of twenty-first century work force demographics on attitudes toward management approaches

Hertle, Sharon Rose, M.S.

San Jose State University, 1990

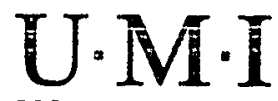

300 N. Zecb Rd.

Ann Arbor, MI 48106 
- 
EFFECTS OF TWENTY-FIRST CENTURY WORK FORCE DEMOGRAPHICS

ON ATTITUDES TOWARD MANAGEMENT APPROACHES

\author{
A Thesis \\ Presented to \\ the Faculty of the Department of Psychology \\ San Jose State University
}

In Partial Fulfillment

of the Reguirements for the Degree

Master of Science

by

Sharon R. Hertle

August, 1990 
APPROVED FOR THE DEPARTMENT OF PSYCHOLOGY

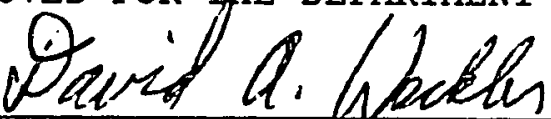

David A. Weckler, Ph.D.

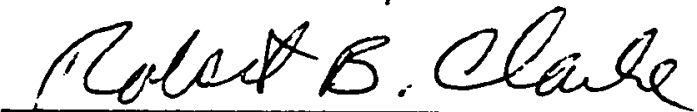

Robert B. Clarke, Ph.D.

Miltax d. Cesulessen Milton L. Andersen, Ph.D.

APPROVED FOR THE UNIVERSITY

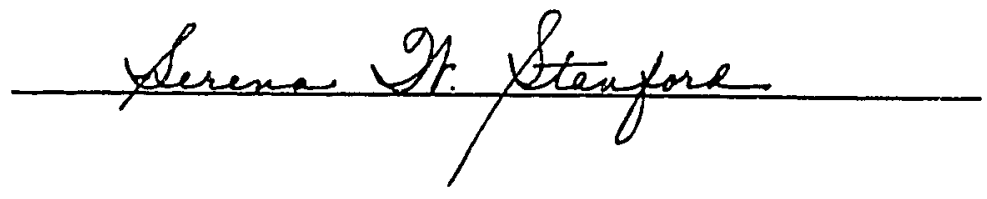


ACKNOWLEDGEMENTS

A sincere thank you to my thesis committee: David A. Weckler, Robert B. Clarke, and Milton L. Andersen. I would also like to thank Robert A. Hicks for his encouragement and Howard Tokunaga for his statistical support. Acknowledgements go to Christine c. Young and the members of the Santa Clara Valley Personnel Association for their assistance and cooperation in this study. Finally, I would like to thank Richard $\mathrm{H}$. Hertle for his untiring patience. 
TABLE OF CONTENTS

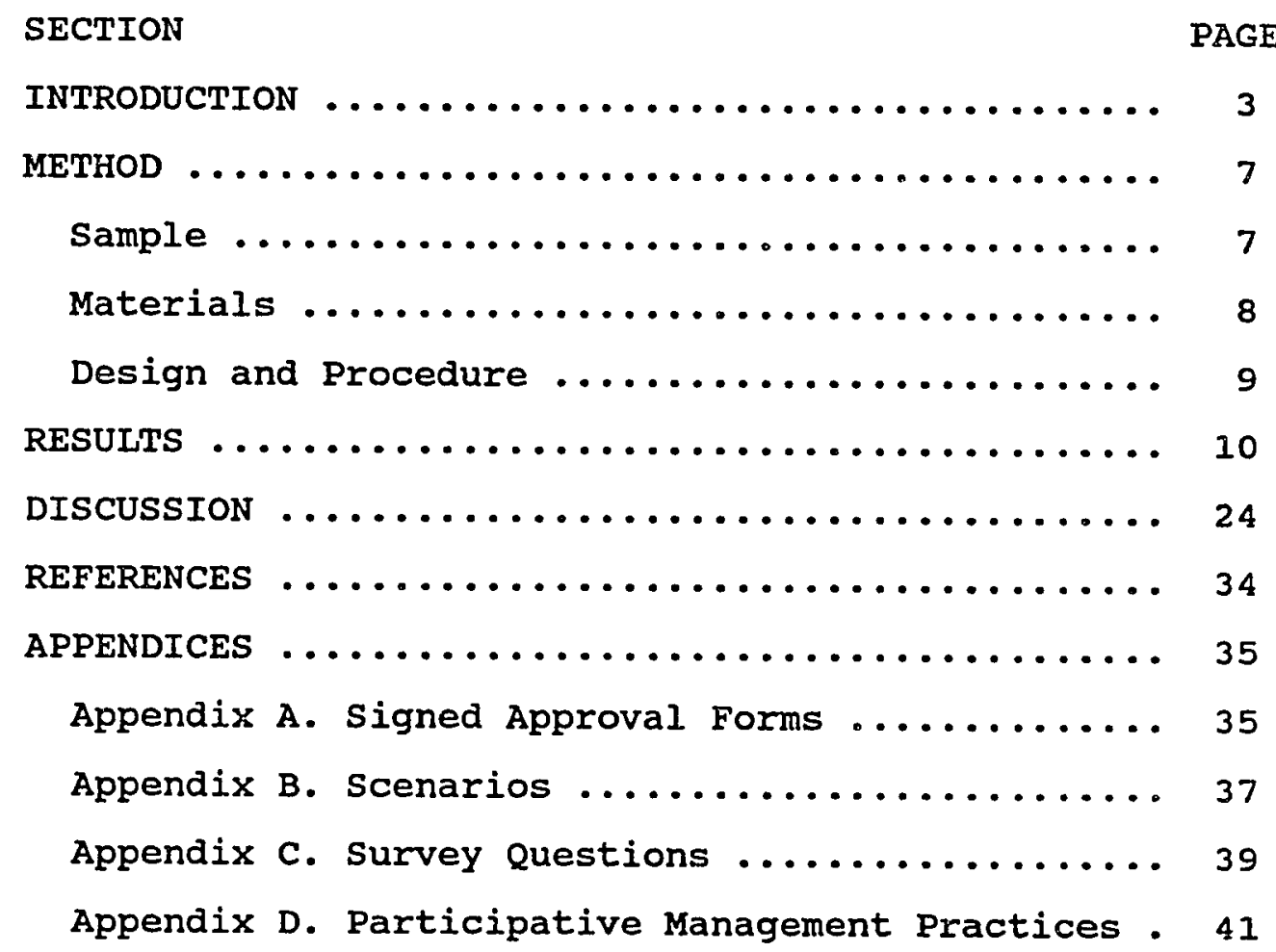


IIST OF TABLES

TABLE

PAGE

1. Mean Response by Participative Management Practice

2. T-test for Difference Between Two Scenario

Category Means

3. Means and ANOVA, Information Subscale

16

4. Means and ANOVA, Knowledge Subscale

17

5. Means and ANOVA, Power Subscale

6. Means and ANOVA, Rewards/Compensation Subscale

19

7. Means and ANOVA, Total Survey

20 
Work Force Demographics

1

Effects of Twenty-First Century Work Force Demographics on Attitudes Toward Management Approaches

Sharon R. Hertle

San Jose State University

Running head: WORK FORCE DEMOGRAPHICS AND MANAGEMENT APPROACHES 
Work Force Demographics

Abstract

Participative management consists of those practices which increase employee involvement in areas which can improve work practices, decision making processes, and organizational performance. Despite the increased interest in and potential benefits of a participative management approach, the effective use of these techniques is not without obstacles. This thesis focuses on the barriers presented by subordinates to the introduction and successful practice of participative management. To empirically analyze the attitudes of human resource experts toward participative management practices, both before and after the introduction of demographic factors representing potential subordinate barriers, a survey was developed and distributed to members of a professional personnel association. The findings of this study indicate that: (a) the human resource experts surveyed are supportive of many of the participative management practices presented; (b) these experts are aware of emerging demographic factors, representing potential subordinate barriers; and (c) the presentation of demographic factors did influence expert attitudes. 
Work Force Demographics

3

Effects of Twenty-First Century Work Force Demographics on Attitudes Toward Management Approaches

"Approaches to organizing and managing people in industry are not inherently effective or ineffective. They are effective to the degree that they fit existing environmental conditions" (Lawler, 1986, p. 12). This suggests that to be effective, a management approach needs to fit the existing business climate, the technology used to produce goods and services, the societal regulations, and the nature of the work force. Because these four environmental factors determine the effectiveness of any management approach, the effectiveness of a given approach may change over time.

Traditional approaches to organizing and managing people in industry are being rendered obsolete. Current environmental conditions are prompting many human resource managers and planners to recommend some form of high-involvement, high-commitment approach to organizing and managing people in industry (Lawler, 1986).

A traditional management approach is based on the premise that individuals in high-level management positions and experts run the business. Decisions are made by supervisory personnel who are knowledgeable within specific disciplines. Information and ideas flow downward from high-level positions in a 
Work Force Demographics

hierarchical structure. Individuals receive only the training which is needed to perform their jobs. Rewards are based on individual performance.

In contrast to traditional management practice, a high-involvement, high-commitment management approach is based on the premise that individuals in all positions participate in running the business. Decisions are made by job-holders or work teams. Information and ideas flow freely among people in a non hierarchical structure. Individuals receive training in job performance, interpersonal skills, problem analysis, decision making, leadership, and business economics. Rewards are based on individual knowledge, skills, and the overall effectiveness of the organization.

The changing nature of the work force is of particular interest to industrial and organizational psychologists. According to Lawler (1986) three important demographic factors are currently impelling movement to a high-involvement, high-commitment management approach. First, many workers are highly educated and have an expectation that they will be able to use their knowledge and skills on the job. Second, an increased awareness of legal and societal rights has resulted in employees who are willing to challenge what they perceive as unfair. Third, individual attitudes 
Work Force Demographics

and values have changed, resulting in workers who want autonomy and responsibility on the job. If true, these three demographic factors suggest that the high-involvement, high-commitment approach should become the best way to manage the existing labor force. There are, however, other emerging demographic factors which may hinder the movement to a high-involvement, high-commitment management approach in the twenty-first century. First, there are increasing levels of illiteracy and decreasing levels of reasoning skills among our youth, resulting in many workers who will not be prepared to participate in knowledge-intensive organizations (Ehrlich, 1988; U.S. Department of Labor \& U.S. Department of Education, 1988). Second, the significant entry into the work force of women, who are traditionally the primary caregivers for young children and aging adults, raises the possibility that an increasing proportion of workers will not make the time commitment required in high-participation organizations (Ehrlich, 1988; Johnston \& Packer, 1987). Third, the significant entry into the work force of minorities and immigrants, who are typically low-skilled, suggests that many individuals will not be prepared to take highly-skilled jobs in participative organizations (Bernstein, 1988; Ehrlich, 1988; Johnston \& Packer, 1987). These three 
Work Force Demographics

demographic factors suggest that many workers entering the labor force between now and the year 2000 will not be well suited for organizations that employ the high-involvement, high-commitment management approach.

Despite the increased interest in and potential benefits of the high-involvement, high-commitment management approach, the effective use of participative management practices is not without obstacles. Four principal types of barriers which can block the introduction and effective use of participative management practices have been identified: organizational, situational, managerial, and subordinate (Anthony, 1978). Of these various obstacles, the potential barriers which subordinates present to the introduction and successful practice of high-involvement, high-commitment management are relevant to this study. Subordinate barriers to increased participation are thought to exist when non-managerial employees lack the knowledge, skills, and time required for effective involvement (Anthony, 1978).

The objective of this study is to determine if the attitudes of a sample of human resource managers and planners toward high-involvement, high-commitment management practices are positive and whether or not these attitudes can be influenced by the introduction 
Work Force Demographics

of demographic factors. Specifically, two research questions are being explored. First, are participative management practices supported by human resource managers and planners? It is expected that human resource experts are generally supportive of participative management practices that move information, knowledge, rewards, and power downward to all employees. Second, are the attitudes of human resource managers and planners toward participative management practices influenced by information describing current and emerging demographic factors? It is expected that current demographic factors will make attitudes toward participative management more positive, and that emerging demographic factors will make attitudes more negative.

Method

Sample

The sample consisted of 65 human resource managers and planners who are members of the Santa clara Valley Personnel Association. There were 43 females and 22 males in the sample with a mean age of 41 years. The mean education level for the sample was 16.6 years and the mean number of years in human resources was 11.4 . Participation in this study was voluntary, and subjects were treated in accordance with the ethical standards of the American Psychological Association. 
Work Force Demographics

Materials

Six brief scenarios were developed based on the demographic factors highlighted by this study. Specifically, demographic data was systematically collected from current books, periodicals and government publications, and then elaborated in scenarios. The scenarios were piloted to ensure the clarity of presented information. Appendix B contains the actual scenarios.

An instrument developed to empirically examine employee and managerial attitudes toward participative management practices provided the starting point from which a survey questionnaire was developed (Gilberg, 1988; Halal \& Brown, 1981). The survey addresses high-involvement, high-commitment versus traditional management practices in order to determine: (a) how committed human resource experts are to a management approach that greatly increases employee involvement in improving work practices, decision making, and organizational performance; and (b) the degree to which human resource experts recommend that information, knowledge, power, and rewards be moved downward to all employees. Specifically, a set of twenty questions answered on a 7-point Likert scale with 4 labeled as "neutral" provide an opportunity for experts to respond positively or negatively toward high-involvement, 
Work Force Demographics

high-commitment management practices. The questions were piloted to ensure their clarity. Appendix C contains the actual survey questions and the 7-point Iikert scale descriptors. Appendix D contains a list of the participative management practices represented by the survey questions.

Design and Procedure

All human resource managers and planners in the sample were first asked to answer four personal and demographic questions. Next, they were asked to describe their attitudes toward high-involvement, high-commitment management practices by responding to twenty survey questions. Half of the sample, randomly selected, examined three scenarios describing current demographic factors (e.g., highly educated workers, employee awareness of legal and societal rights, and workers who value job autonomy and responsibility). The other half of the sample examined three scenarios describing emerging demographic factors (e.g., increasing levels of illiteracy among young workers, high numbers of female workers as primary caregivers, and many low-skilled minority and immigrant workers). Both groups were asked to estimate the probabilities that examined scenarios will be prevalent in the twenty-first century on a scale ranging from 1 (Very low) to 7 (Very high). Finally, all experts were asked 
Work Force Demographics

to respond once more to the original twenty survey questions. For this final response they were instructed to assume that the three scenarios they read represent reality, and to project how these scenarios influence their attitudes toward high-involvement, high-commitment management practices.

Results

\section{Initial Survey Responses}

The survey responses of all human resource experts, prior to exposure to demographic scenarios, indicate that they are in agreement with over half of the participative management practices described in the survey. However, expert responses also indicate neutrality and disagreement with respect to several of the participative management techniques presented. In general, the sample agrees $(M>4.5)$ with the following thirteen practices associated with participative management: Practice 1, Problem-solving Committees; Practice 2, Attitude Surveys; Practice 4, Gain Sharing; Practice 7, Interpersonal/Group skills Training; Practice 8, Company Operating Results shared; Practice 10, Quality Circles; Practice 11, Profit Sharing; Practice 13, Work Team cross Training; Practice 14, Unit Operating Results Shared; Practice 15, Strategic Plans Shared; Practice 17, Enriched/ Redesigned Jobs; Practice 18, Competitor Performance 
Work Force Demographics

Data Shared; and Practice 19, Self-managing work Teams. The sample disagrees $(\underline{M}<3.4)$ with the following three practices: Practice 3, Employee Leader Selection; Practice 5, Employment Security; and Practice 6, Employee staffing Input. The sample remains neutral $(3.5<\underline{M}>4.4)$ on the following four practices: Practice 9, Employee Policy-making Representation; Practice 12, Technical/Analytical skills Training; Practice 16, Work Team Peer Review; and Practice 20, Knowledge/Skill-based Pay systems. A summary of the total number of responses, mean response, and standard deviation for each participative management practice is provided in Table 1 .

Scenario Probabilities

Each group of human resource experts also rated either three positive scenarios (representing current demographic factors) or three negative scenarios (representing emerging demographic factors) for their probability of prevalence in the twenty-first century on a scale ranging from 1 (Very low) to 7 (Very high). A t-test was used to determine if experts who received the positive scenarios rated them more or less probable than those who received the negative scenarios. Although both groups rated their respective scenarios in the direction of probable ( $\underline{M}>4)$, the mean probability for the negative scenarios was found to be 
Work Force Demographics

Table 1

Mean Response by Participative Management Practice

\begin{tabular}{|c|c|c|c|}
\hline Practice & $\begin{array}{l}\text { Total \# } \\
\text { Responses }\end{array}$ & $\begin{array}{c}\text { Mean } \\
\text { Response }\end{array}$ & $\underline{\underline{S D}}$ \\
\hline Problem-solving Committees & 65 & 5.50 & 1.58 \\
\hline Attitude surveys & 65 & 5.75 & 1.20 \\
\hline Employee Leader Selection & 65 & 2.57 & 1.32 \\
\hline Gain Sharing & 65 & 5.85 & 1.03 \\
\hline Employment security & 65 & 2.95 & 1.57 \\
\hline Employee staffing Input & 65 & 3.41 & 1.71 \\
\hline $\begin{array}{l}\text { Interpersonal/Group } \\
\text { Skills Training }\end{array}$ & 65 & 5.79 & 1.42 \\
\hline $\begin{array}{l}\text { Company Operating } \\
\text { Results Shared }\end{array}$ & 65 & 6.32 & 1.17 \\
\hline $\begin{array}{l}\text { Employee Policy-making } \\
\text { Representation }\end{array}$ & 65 & 4.28 & 1.82 \\
\hline Quality Circles & 65 & 5.85 & 1.03 \\
\hline Profit Sharing & 55 & 5.66 & 1.31 \\
\hline $\begin{array}{l}\text { Technical/Analytical } \\
\text { Skilis Training }\end{array}$ & 65 & 4.06 & 1.71 \\
\hline Work Team Cross Training & 65 & 5.63 & 1.07 \\
\hline $\begin{array}{l}\text { Unit Operating Results } \\
\text { Shared }\end{array}$ & 65 & 6.45 & 0.71 \\
\hline Strategic Plans Shared & 65 & 6.36 & 1.07 \\
\hline Work Team Peer Review & 65 & 4.43 & 1.72 \\
\hline Enriched/Redesigned Jobs & 65 & 5.86 & 1.03 \\
\hline $\begin{array}{l}\text { Competitor Peformance } \\
\text { Data Shared }\end{array}$ & 65 & 5.39 & 1.49 \\
\hline Self-managing Work Teams & 65 & 4.80 & 1.45 \\
\hline $\begin{array}{l}\text { Knowledge/skill-based } \\
\text { Pay Systems }\end{array}$ & 65 & 3.83 & 1.62 \\
\hline
\end{tabular}


Work Force Demographics

significantly higher than the mean probability for the positive scenarios $[\underline{t}(63)=2.55, \underline{p}<.01$, two tailed]. This difference between means suggests that human resource experts have some awareness of emerging demographic factors, and perceive as most likely, the three scenarios that depict a less skilled and less committed work force. Table 2 shows the number of subjects, mean probability, and standard deviation for each scenario category. Final Survey Responses

The statistical design used to test for treatment differences was a two-ractor mixed design with repeated measures on one factor. The between-subjects variable had two levels corresponding to the two groups, those examining the positive scenarios describing current demographic factors and those examining the negative scenarios describing emerging demographic factors. The within-subjects factor represented the pre and post scenario exposure measures (hereafter referred to as time one and time two) of attitudes toward participative management practices.

since the twenty questions on the survey were selected to represent four different aspects of participative management, the items were sorted to yield four management practices subscales (e.g., relating to information, knowledge, power, and rewards) 
Work Force Demographics

Table 2

T-test for Difference Between Two Scenario

Category Means

\begin{tabular}{lcccccc}
\hline Scenarios & $\underline{n}$ & $\begin{array}{c}\text { Mean } \\
\text { Probability }\end{array}$ & $\underline{\text { SD }}$ & $\underline{\text { df }}$ & $\underline{t}$ & $\underline{p}$ \\
\hline Positive & 32 & 4.45 & 1.17 & & & \\
Negative & 33 & 5.17 & 1.12 & 63 & 2.55 & .01 \\
\hline
\end{tabular}

Note. The scenarios were rated on a 7-point likert scale wherein a response of $1=$ Very low probability and a response of $7=$ very high probability. 
Work Force Demographics

and separate two-factor ANOVAs were performed on each subscale. A two-factor ANOVA was also utilized to examine the twenty item survey as a whole. All five ANOVAs yielded statistically significant Group $x$ Time interactions, which indicates as predicted that the groups were differentially influenced by the presentation of demographic factors in the form of scenarios. Means and ANOVA summaries can be found in Tables 3, 4, 5, 6, and 7 .

Follow up tests were performed for all four participative management subscales (e.g., information, knowledge, power, and rewards) and the twenty item survey as a whole. specifically, pairwise comparisons were used to examine any changes in the positive group (those eventually receiving the positive demographic scenarios) and any changes in the negative group (those eventually receiving the negative demographic scenarios) from time one to time two. Pairwise comparisons were also used to examine any differences between the positive and negative groups at time one and at time two.

Analysis of the information subscale indicates no change in the positive group ratings from time one $(\underline{M}=$ $6.32)$ to time two $(\underline{M}=6.35), \underline{F}(1,31)=.116$, but a significant decrease in the negative group ratings from time one $(\underline{M}=5.94)$ to time two $(\underline{M}=5.68), E(1,32)=$ 
Work Force Demographics

Table 3

Means and Analysis of Variance of the Information subscale

\begin{tabular}{lcc}
\hline & \multicolumn{2}{c}{ Attitude Measures } \\
\cline { 2 - 3 } Group & Time one & Time Two \\
\hline Positive & 6.32 & 6.35 \\
Negative & 5.94 & 5.68 \\
\hline
\end{tabular}

\begin{tabular}{|c|c|c|c|c|}
\hline Source & $\underline{\mathrm{df}}$ & $\underline{\text { MS }}$ & $\underline{\mathbf{E}}$ & \\
\hline \multicolumn{5}{|l|}{ Between Ss } \\
\hline Groups & 1 & 8.88 & 9.56 & ** \\
\hline Error between & 63 & 0.93 & & \\
\hline \multicolumn{5}{|l|}{ witnin Ss } \\
\hline Times & 1 & 0.44 & 3.83 & $*$ \\
\hline $\mathbf{G} \times \mathbf{T}$ & 1 & 0.68 & 5.96 & $*$ \\
\hline Error within & 63 & 0.11 & & \\
\hline
\end{tabular}

$* \underline{p}<.05$.
$* * \underline{p}<.001$. 
Work Force Demographics

Table 4

Means and Analysis of Variance of the Knowledge Subscale

\begin{tabular}{lcc}
\hline & \multicolumn{2}{c}{ Attitude Measures } \\
\cline { 2 - 3 } Group & Time one & Time Two \\
\hline Positive & 5.23 & 5.42 \\
Negative & 5.08 & 4.94 \\
\hline
\end{tabular}

\begin{tabular}{|c|c|c|c|c|}
\hline Source & $\underline{d f}$ & $\underline{\text { MS }}$ & $\underline{\mathbf{F}}$ & \\
\hline \multicolumn{5}{|l|}{ Between Ss } \\
\hline Groups & 1 & 3.31 & 1.91 & \\
\hline Error between & 63 & 1.74 & & \\
\hline \multicolumn{5}{|l|}{ within Ss } \\
\hline Times & 1 & 0.02 & 0.12 & \\
\hline$G \times T$ & 1 & 0.81 & 4.32 & $\neq$ \\
\hline Error within & 63 & 0.19 & & \\
\hline
\end{tabular}


Work Force Demographics

Table 5

Means and Analysis of Variance of the Power Subscale

\begin{tabular}{llc}
\hline & \multicolumn{2}{c}{ Attitude Measures } \\
\cline { 2 - 3 } Gxoup & Time One & Time Two \\
\hline Positive & 5.09 & 5.28 \\
Negative & 4.35 & 4.16 \\
\hline
\end{tabular}

\begin{tabular}{|c|c|c|c|c|}
\hline Source & $\underline{d f}$ & $\underline{\text { MS }}$ & $\underline{\mathbf{F}}$ & \\
\hline \multicolumn{5}{|l|}{ Between Ss } \\
\hline Groups & 1 & 27.96 & 34.72 & ** \\
\hline Error between & 63 & 0.81 & & \\
\hline \multicolumn{5}{|l|}{ Within Ss } \\
\hline Times & 1 & 0.00 & 0.00 & \\
\hline $\mathbf{G} \mathbf{x} \mathbf{T}$ & 1 & 1.20 & 5.70 & * \\
\hline Error within & 63 & 0.21 & & \\
\hline \multicolumn{5}{|l|}{$\star \quad \underline{p}<.05$} \\
\hline$* * \underline{p}<.001$. & & & & \\
\hline
\end{tabular}


Work Force Demographics

Table 6

Means and Analysis of Variance of the Rewards/Compensation Subscale

\begin{tabular}{lcc}
\hline & \multicolumn{2}{c}{ Attitude Measures } \\
\cline { 2 - 3 } Group & Time one & Time Two \\
\hline Positive & 4.67 & 5.04 \\
Negative & 4.47 & 4.50 \\
\hline
\end{tabular}

\begin{tabular}{|c|c|c|c|c|}
\hline Source & $\underline{d f}$ & MS & $\underline{F}$ & \\
\hline \multicolumn{5}{|l|}{ Between Ss } \\
\hline Groups & 1 & 4.53 & 3.25 & * \\
\hline Error between & 63 & 1.39 & & \\
\hline \multicolumn{5}{|l|}{ within Ss } \\
\hline Times & 1 & 1.22 & 5.73 & ** \\
\hline$G \times T$ & 1 & 0.87 & 4.08 & ** \\
\hline Error within & 63 & 0.21 & & \\
\hline
\end{tabular}

* $\underline{p}<.10$.

$\star * \underline{\underline{p}}<.05$. 
Work Force Demographics

Table 7

Means and Analysis of Variance of the Total Survey

\begin{tabular}{lcc}
\hline & \multicolumn{2}{c}{ Attitude Measures } \\
\cline { 2 - 3 } Group & Time one & Time Two \\
\hline Positive & 5.27 & 5.47 \\
Negative & 4.80 & 4.65 \\
\hline
\end{tabular}

\begin{tabular}{llll}
\hline Source & df & $\underline{\text { MS }}$ & $\underline{F}$ \\
\hline
\end{tabular}

Between Ss

\begin{tabular}{|c|c|c|c|}
\hline Groups & 1 & 13.49 & 23.04 \\
\hline Error between & 63 & 0.59 & \\
\hline
\end{tabular}

within Ss

$\begin{array}{lrrr}\text { Times } & 1 & 0.01 & 0.14 \\ \text { G X T } & 1 & 0.96 & 10.37 \\ \text { Error within } & 63 & 0.09 & \end{array}$ *

$* \underline{p}<.001$. 
Work Force Demographics

9.8, $\underline{p}<.01$. There was a significant difference between the groups prior to the different treatments (presentation of positive or negative demographic scenarios). The mean for the group randomly selected to receive the positive scenarios was higher ( $\underline{M}=$ 6.32) than the mean for the group randomly selected to receive the negative scenarios $(\underline{M}=5.94), \underline{F}(1,63)=$ 20.4, $\mathrm{p}<.01$. After the experimental manipulation the difference between the groups was even greater, with the mean for the positive scenario group ( $\underline{M}=$ 6.35) higher than the mean for the negative scenario group $(\underline{M}=5.68), \underline{F}(1,63)=63.4, \underline{p}<.01$.

For the knowledge subscale there was a significant increase in the positive group ratings from time one (M $=5.23)$ to time two $(\underline{M}=5.42), \underline{F}(1,31)=4.8, \underline{p}<$ .05 , but no change in the negative group ratings from time one $(\underline{M}=5.08)$ to time two $(\underline{M}=4.94), \underline{F}(1,32)=$ 1.5. There was no significant difference between the groups prior to the different treatments (presentation of positive or negative demographic scenarios). The mean for the group randomly selected to receive the positive scenarios was 5.23 and for the group randomly selected to receive the negative scenarios was $5.08, \underline{F}$ $(1,63)=2.24$. After the experimental manipulation there was a significant difference between the groups, with the mean for the positive scenario group ( $\underline{M}=$ 
Work Force Demographics

5.42) higher than the mean for the negative scenario group $(\underline{M}=4.94), \underline{F}(1,63)=19.7, \underline{p}<.01$.

Analysis of the power subscale indicates no significant change in the positive group ratings from time one $(\underline{M}=5.09)$ to time two $(\underline{M}=5.28), \underline{F}(1,31)=$ 2.8, and no significant change in the negative group ratings from time one $(\underline{M}=4.35)$, to time two $(\underline{M}=$ 4.16), $E(1,32)=2.9$. There was a significant difference between the groups prior to the different treatments (presentation of positive or negative demographic scenarios). The mean for the group randomly selected to receive the positive scenarios was higher $(\underline{M}=5.09)$ than the mean for the group randomly selected to receive the negative scenarios $(\underline{M}=4.35)$, $\underline{F}(1,63)=41.7, \underline{p}<.01$. After the experimental manipulation the difference between the groups was even greater, with the mean for the positive scenario group $(\underline{M}=5.28)$ higher than the mean for the negative scenario group $(\underline{M}=4.16), \underline{F}(1,63)=96.7, \underline{p}<.01$.

For the rewards/compensation subscale there was a significant increase in the positive group ratings from time one $(\underline{M}=4.67)$ to time two $(\underline{M}=5.04), \underline{F}(1,31)=$ 9.59, $\underline{p}<.01$, but no change in the negative group ratings from time one $(\underline{M}=4.47)$ to time two $(\underline{M}=4.50$, $\underline{F}(1,32)=.07$. There was no significant difference between the groups prior to the different treatments 
Work Force Demographics

(presentation of positive or negative demographic scenarios). The mean for the group randomly selected to receive the positive scenarios was 4.67 and for the group randomly selected to receive the negative scenarios was $4.47, \underline{F}(1,63)=3.4$. After the experimental manipulation there was a significant difference between the groups, with the mean for the positive scenario group $(\underline{M}=5.04)$ higher than the mean for the negative scenario group $(\underline{M}=4.50), \underline{F}(1,63)=$ $22.0, \underline{\mathrm{p}}<.01$.

Finally, analysis of the whole twenty item survey indicates a significant increase in the positive group ratings from time one $(\underline{M}=5.27)$ to time two ( $\underline{M}=$ 5.47), $\underline{F}(1,31)=6.34, \underline{p}<.05$, and a significant decrease in the negative group ratings from time one (M $=4.80)$ to time two $(\underline{\mathrm{M}}=4.65), \underline{\mathrm{F}}(1,32)=4.1, \underline{\mathrm{p}}<$ .05. There was a significant difference between the groups prior to the different treatments (presentation of positive or negative demographic scenarios). The mean for the group randomly selected to receive the positive scenarios was higher $(\underline{M}=5.27)$ than the mean for the group randomly selected to receive the negative scenarios $(\underline{M}=4.80), \underline{F}(1,63)=39.4, \underline{p}<.01$. After the experimental manipulation the difference between the groups was even greater, with the mean for the positive scenario group $(\underline{M}=5.47)$ higher than the mean 
Work Force Demographics

for the negative scenario group $(\underline{M}=4.65), \underline{F}(1,63)=$ $117.3, \underline{p}<.01$.

\section{Discussion}

\section{Initial Survey Responses}

One of the primary goals of this study was to determine the initial degree of receptivity of a sample of human resource managers and planners toward specific participative management practices. Using a survey questionnaire with human resource experts employed in a variety of Santa clara Valley organizations lead to the following general conclusions: (a) there is fairly strong support for the practice of sharing information at all levels of an organization, (b) there is moderate support for moving knowledge and rewards down to all levels of an organization, and (c) there is moderate support for moving power down to all levels of an organization even though some of the techniques of empowering employees considered more "progressive" are not supported.

Human resource experts favor information sharing in the form of providing company/unit operating results and strategic plans, and are supportive of sharing information regarding competitors throughout the organization. This suggests some commitment to the sharing of information that is basic to employee involvement or participation at all levels of an 
Work Force Demographics

organization.

In the knowledge category, human resource experts agree that interpersonal and group skills training should be received by all employees. This indicates an interest in providing individuals with the skills necessary for increased participation which involves meetings, interpersonal interaction, and influencing others. Respondents also agree that work teams should be cross trained. This suggests support for the type of training where individuals are exposed to different skills/tasks and participate in several different parts of the work unit. Finally, respondents remain neutral on providing technical and analytical skills training to all employees. It seems that these experts have yet to decide whether it is advantageous for employees to receive this type of training (i.e., quality analysis, statistics, finance, etc.).

In the rewards or compensation category, human resource experts support the use of incentive systems that tie employees into, and reward them for, the success of the business (e.g., profit sharing and gain sharing). However, respondents remain neutral on developing knowledge/skill-based pay systems which reduce the distinctions between classifications of employees and reward individuals based on learned skills and specific contributions. Finally, 
Work Force Demographics

respondents do not support the development of written employment security policies. Lack of support in this area, however, may be a reaction to the uncertain economic conditions that organizations face.

In the empowerment category, human resource experts favor enriching and redesigning jobs so that all employees have increased skill variety, autonomy, identity with the task, and performance feedback. Respondents slightly favor the use of self-managed work teams which are highly autonomous (in some cases acting without supervision) and often responsible for a whole product or service. However, respondents remain neutral when asked if self-managed work teams should be involved in setting performance standards and evaluating their peers. Also in the empowerment category, human resource experts favor special meetings and participative activities where employees provide input to the planning, decision making, and problem solving processes (e.g., attitude surveys, quality circles, and problem solving groups or task forces). One exception, however, is that human resource experts remain neutral regarding employee representation on the board of directors of an organization. Finally, human resource experts do not favor employee leader selection and employee staffing input. Apparently, human resource experts are not ready to extend employee 
Work Force Demographics

involvement to the personnel decision making arena. overall, the human resource experts surveyed are supportive of many of the approaches to moving information, knowledge, rewards, and power throughout an organization. However, these same human resource experts fall short of a total and indiscriminate commitment to managing an organization in a highly participative manner. These findings are not particularly surprising since the highly participative approach to managing people is often described as an "idealistic model" that involves considerable personal/organizational effort and risk (Lawler, 1986). As a result, many organizations test the waters of participative management quite gradually by trying out a few of the employee involvement techniques, usually with a small percentage of employees. Recent studies, however, show that companies who are making a substantial effort to move information, knowledge, rewards, and power to the entire employee population are the ones reporting a positive impact on product/service quality, work productivity, and employee motivation (Lawler, 1986). Such data support the notion that the key to success for high-involvement, high-commitment organizations is consistency and congruence. simply stated, the employee involvement policies 
Work Force Demographics

$i$

and practices implemented must fit together and affect everyone in the organization equally if participative management is to be successful. When information is shared with all employees they have the foundation to use their knowledge, skills, and abilities; knowledge sharing gives employees the opportunity to learn new skills; the reward system reinforces learning and "stellar" performance; and the sharing of power encourages employees to take risks and fully utilize their skills.

Scenario Probabilities

In order to tap experts' beliefs about probable future work force characteristics, all human resource managers and planners in the sample were asked to estimate the probabilities that examined scenarios will be prevalent in the twenty-first century. The human resource experts surveyed do appear to have some awareness of the demographic trends and twenty-first century labor force projections. In fact, despite their generally positive attitudes toward participative management practices and their average prediction that both positive and negative work force scenarios are more likely than not, human resource experts indicated that the negative scenarios are significantly more likely than the positive ones. If this finding holds up as an estimate for the population, and if it proves 
Work Force Demographics

accurate, one must question the accuracy and wisdom of strategic planning that depends on a work force predominately composed of highly educated, highly skilled, and highly motivated individuals.

The vastly different labor force which is emerging as we approach the twenty-first century will pose unique challenges for human resource experts in the area of participative management. Before an organization can expect to fully utilize the contributions of all employees, human resource experts will be required to diagnose and overcome potential barriers to increased employee involvement. For example, it will be important to select new employees with the appropriate skills and abilities, or to train those with poor basic skills; existing employees will require an increasingly high level of reading, computation, communication, and reasoning skills; and it will be necessary to keep all employees motivated and interested in contributing to the success of the business.

\section{Final Survey Results}

One final primary goal of this study was to determine whether or not the attitudes of a sample of human resource managers and planners toward participative management practices could be influenced by the presentation of demographic factors 
Work Force Demographics

characteristic of the current (positive scenarios) and emerging (negative scenarios) work force. After responding to the initial questionnaire, human resource experts were presented with either three positive or three negative scenarios and once again asked to respond to the original survey questions. Their responses lead to the conclusion that they were influenced by the manipulation and that, in general, these experts do view work force characteristics as important in making the decision to increase or decrease the use of participative management practices.

For all four participative management subscales (e.g., relating to information, knowledge, power, and rewards) and the twenty item survey as a whole, it was expected that current (positive) demographic factors would make attitudes toward participative management more positive, and that emerging (negative) demographic factors would make attitudes more negative. As predicted, the human resource experts sampled increased their adherence to progressive employee involvement practices when contemplating a highly qualified and committed work force and decreased their basically positive attitudes when contemplating a work force less qualified or committed.

For two of the subscales (e.g., information and power) and for the twenty item survey as a whole, the 
Work Force Demographics

two groups, prior to exposure to demographic scenarios had significantly different ratings. Specifically, the group that was randomly selected to receive the positive scenarios came in with higher ratings than the group that was randomly selected to receive the negative scenarios. This occurred even though all 65 human resource experts received the same information at the beginning of the survey, responded to the same questions before reading the scenarios, and were sent the positive or negative scenarios at random. Although these initial differences between groups cannot be adequately explained, it does not detract from the fact that after the experimental manipulation there were significant differences between the groups on all four subscales and the total survey and, in particular, increased differences between the groups on the information, power, and total survey scales. Since these initial differences were in the same direction as the expected effects of the manipulation, they might well have masked any effects of the manipulation. But this was not the case. Although the differences in means were small, the group reading the positive scenarios became more positive in their views, and the group reading the negative scenarios became more negative in their views. 
Work Force Demographics

Conclusion

Participative management practices stress active involvement by all employees in the important processes of an organization. They rest on the concept of sharing information, knowledge, power, and rewards at all levels of an organization. However, the successful introduction and implementation of participative management practices also raises a number of issues concerning employee motivation and the skills/abilities of the labor force. Lawler believes that participative management is an idea whose time has come (1986). He contends that the participative approach to management meets today's organizational needs because our existing labor force is highly educated and committed. However, there are important changes beginning to take place in the labor force as we approach the twenty-first century inat suggest that the emerging work force may not be as educated, skilled, or committed as the present work force (Johnston \& Packer, 1987; U.S. Department of Labor, 1988). Because of these changes, human resource experts will need to understand what motivates employees, to assess which skills/abilities employees have, to determine what demotivators exist, and to recognize employee shortcomings which must be overcome before participative forms of management can be successfully implemented and practiced. 
Work Force Demographics

In summary, the human resource managers and planners in this study appear to have some awareness that important changes in the labor force are emerging. If the sample had not shown an awareness of emerging demographic trends it would be logical to conclude that they had not given much thought to how labor force changes will impact future human resource practices, including the implementation and success of more participative forms of management. However, their apparent awareness of emerging demographic trends implies that the human resource experts sampled are beginning to think about how labor force changes may make some participative management techniques less appropriate. 
Work Force Demographics

References

Anthony, W.P. (1978). Participative management, Reading, MA: Addison-Wesley.

Bernstein, A. (1988, september 19). Where the jobs are is where the skills aren't. Business Week, 104-106.

Ehrlich, E. (1988, September 19). For American business a new world of workers. Business Week, 112-120.

Gilberg, J. (1988). Managerial attitudes toward participative management programs: Myths and reality. Public Personnel Management, 17, 109-123.

Halal, W.E., \& Brown, B.S. (1981). Participative management: Myth and reality. California Management Review, 23, 20-32. Johnston, W.B., \& Packer, A.H. (1987). Workforce 2000. Indianapolis, IN: Hudson Institute. Lawler, E.E. (1986) . High-involvement management. San Francisco, CA: Jossey-Bass. U.S. Department of Labor. (1988). Workforce 2000. Washington, D.C.: U.S. Government Printing office.

U.S. Department of Labor, \& U.S. Department of Education. (1988). The bottom line: Basic skills in the workplace. Washington, D.C.: U.S. Government Printing office. 

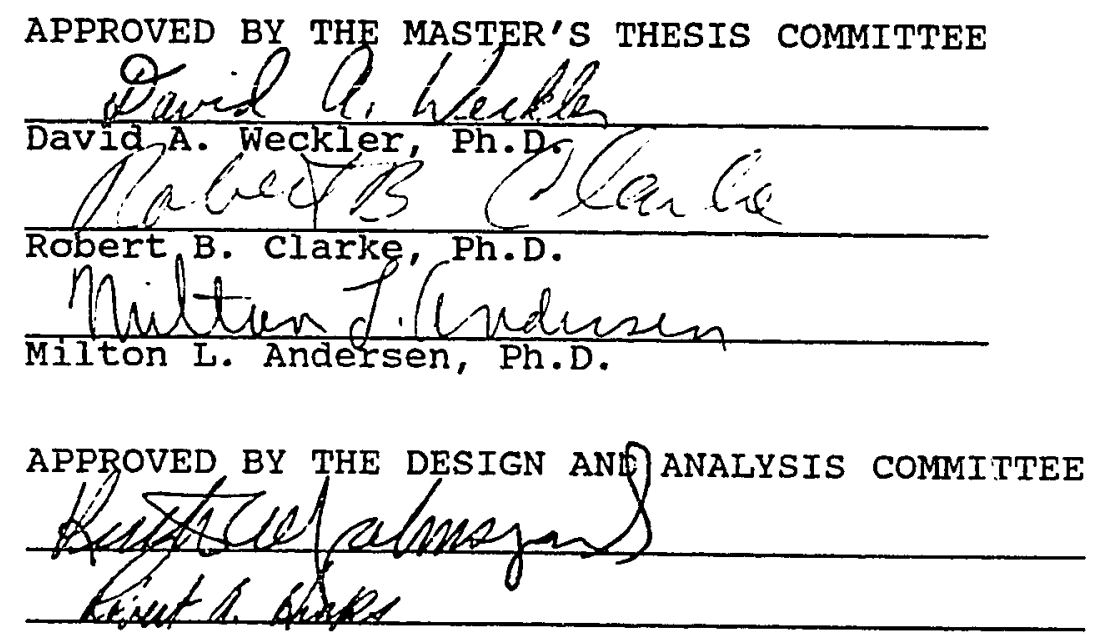
To: Sharon R. Hertle, Psychology

2485 Golf Links Cir.

Santa Clara, CA, 95050

From: Charles R. Bolz

Office of Graduate Studies and Research

Date: February 19, 1990

The Human Subjects Institutional Review Board has approved your request to use human subjects in the study entitled:

"Work Force Demographics and Management Approaches"

This approval is contingent upon the subjects participating in your research project being appropriately protected from risk. This includes the protection of the anonymity of the subjects' identity when they participate in your research project, and with regard to any and all data that may be collected from the subjects. The Board's approval includes continued monitoring of your research by the Board to assure that the subjects are being adequately and properly protected from such risks. If at any time a subject becomes injured or complains of injury, you must notiry Dr. Serena stanford immediately. Injury includes but is not limited to bodily harm, psychological trauma and release of potentially damaging personal information.

Please also be advised that each subject needs to be fuliy informed and aware that their participation in your research project is voluntary, and that he or she may withoraw from the project at any time. Further, a subject's participation, refusal to participate or withdrawal will not affect any services the subject is receiving or will receive at the institution in which the research is being conducted.

If you have any questions, please contact Dr. Stanford or me at (408) 924-2480.

cc: David A. Weckler, Ph. D. 
Work Force Demographics

Appendix B

Scenarios (Positive)

Scenario A

More and more people are finishing high school, going to college, and enrolling in continuing education programs. As a result, American workers are the most educated in the world. Labor Department statistics indicate that 59.7 percent of the work force have high school diplomas and 25 percent of the work force are college graduates. These workers have expectations that they will be able to use the knowledge they acquired in school and often view their education as time invested to obtain a good job.

\section{Scenario B}

More and more people are increasingly conscious of their job rights or individual rights to dignity, self-expression, and due process. As a result, American workers expect to "have a say" in organizational decisions and often challenge what they perceive as unfair or arbitrary decision making on the part of management. These workers are comfortable in a society where both the political and work structures are participative and democratic.

\section{Scenario C}

More and more people value jobs where they can utilize a variety of skilis, be responsible for task outcomes, and have the freedom to decide how the task will be done. As a result, American workers derive authority or power from expertise rather than position. These yorkers, however, have fewer needs for dominance and for deferring to authority which means they are less interested in both ordering others and being ordered by others. 
Work Force Demographics

Appendix B

Scenarios (Negative)

Scenario A

More and more employers are telling U.S. schools that too many graduates come to them unprepared. Education Department statistics indicate that only 70 percent of U.S. students graduate from high school. of those who do finish high school, 25 percent cannot read or write at the eighth-grade level. With the labor force continuing to grow at a slow rate (the result of a decline in birth rates) and with the smaller reservoir of well-educated workers, employers are forced to accept the less well-educated to fill new and existing jobs.

\section{Scenario B}

More and more women are entering the work force. Labor Department statistics indicate that women with children younger than 6 make up the fastest growing segment of the entire work force. Additionally, 73 percent of all working women are of childbearing age, and a growing number of working women between 35 and 54 provide care to aging parents. For many such women balancing work life with parenting and elder-care prevents them from making the time commitment required in many

organizations.

\section{Scenario C}

More and more minorities and immigrants are entering the work force. Labor Department statistics indicate that about half of all new work force entrants are minorities and immigrants. Blacks and Hispanics have the highest school aropout rates in this country and, on average, are low-skilled. Most immigrants lack a high school education and, on average, are less skilled than native-born workers. Continuing technological changes impose an increased reading, writing, and math requirement for the fastest job growth sector (high-skill occupations). Minorities and immigrants are finding it difficult to keep pace with these changing job requirements. 
Work Force Demographics

Appendix C

Survey Questions

1. Employee participation groups (i.e., task teams or work councils) should be empowered to develop and implement changes that improve both organizational performance and quality of employee work life.

2. Data from routine employee attitude surveys should be used to improve work or the work environment.

3. Employees in the various units or work areas of an organization should select their own group leaders or supervisors.

4. Some portion of gains in quality, productivity, cost effectiveness, or other performance indicators should be shared in the form of bonuses with all employees in a unit or work area.

5. An organization should offer employment security by developing a written policy designed to prevent layoffs.

6. Existing employees in the various units or work areas of an organization should be asked for their input before staffing decisions are made (i.e., hiring, firing, etc.).

7. All employees should receive training in interpersonal interaction and group skills (i.e., leadership, team-building, group decision making/problem solving skilis).

8. Company operating results should be shared with all employees.

9. Employees should be represented on the Board of Directors of an organization by an elected leader.

10. Structured employee participation groups (i.e., quality circles) from the various units or work areas of an organization should meet regularly to identify and suggest quality, productivity, and cost improvements. 
Work Force Demographics

Appendix C

Survey Questions

11. A bonus plan that shares some portion of company profits with all employees should be a regular component of compensation. (This does not include dividend sharing.)

12. All employees should receive training in technical and analytical skilis (i.e, accounting, finance, quality/statistical analysis skills).

13. The members of self-managed or autonomous work teams should be cross-trained on all the various tasks that fall within the responsibility of the team.

14. Unit or work area operating results should be shared with participating employees.

15. Information on the business plans and goals of the organization should be shared with all employees.

16. The members of self-managed or autonomous work teams should develop performance standards and participate in evaluating their peers according to these standards.

17. All jobs should be designed or enriched to increase skill variety, autonomy, significance of the task, and performance feedback.

18. Data on competitors' performance should be provided to âi empioyees.

19. Self-managing or autonomous work teams should be responsible for a whole product or service, and make decisions about task assignments, work methods, and work pacing.

20. Knowledge or skill-based pay systems should be put into practice so that pay levels are based on how many skilis employees have and how many jobs they potentially can do.

Note. A 7-point Likert scale was utilized wherein a response of $1=$ strongly disagree, $2=$ Disagree, $3=$ Slightly disagree, $4=$ Neutral, $5=$ slightiy agree, $6=$ Agree, and' $7=$ strongly' agree. 


\section{Work Force Demographics}

\section{Appendix D \\ Participative Management Practices}

Information:

8. Company Operating Results shared

14. Unit Operating Results shared

15. Strategic Plans Shared

18. Competitor Performance Data Shared

Knowledge:

7. Interpersonal/Group Skills Training

12. Technical/Analytical Skills Training

13. Work Team Cross Training

Power:

1. Problem-solving Committees

2. Attitude surveys

3. Employee Leader Selection

6. Employee Staffing Input

9. Employee Policy-making Representation

10. Quality circles

16. Work Team Peer Review

17. Enriched/Redesigned Jobs

19. Self-managing Work Teams

Rewards/Compensation:

4. Gain Sharing

5. Employment security

11. Profit sharing

20. Knowledge/Skill-based Pay systems 